\title{
Regional Green Development and Spatial Evolution in China: Abiding by Theory of Dissipative Structure
}

\author{
Fumin Deng ${ }^{1}$, Hui Zhu', and Xuedong Liang, ${ }^{2 *}$ \\ ${ }^{1}$ The Economy and Enterprise Development Institute, Sichuan University, 610065 Chengdu, P.R. China \\ ${ }^{2}$ Business School, Sichuan University, 610065 Chengdu, P.R. China
}

\begin{abstract}
Regional green development can commendably abide by the theory of dissipative structure. The relative dissipative characteristics taken on by regional development are analyzed, in which the energy factors and resources factors are incorporated into the green economic development and green environment support subsystems (2GE system) in line with the definite input characteristics. A more representative indicator system is established, with positive and negative entropy indexes involved. As Brusselator model and information entropy method are employed to calculate the data of 30 China's provinces from 2008 to 2015, the findings bespeak that green development in China lays particular stress on green economic development assuming higher environment pressure and cost. The development among various regions is getting progressively and evidently different, which is manifested as potent economic base and abundant natural resources in the Eastern China; the backward green economic development and the progress of green environment in Central China; the pursuit of green economic development at the expense of the green environment in Western China and Northeastern China.
\end{abstract}

\section{Introduction}

In the fifth Plenary Session of the 18th CPC Central Committee, the party prioritized "green development" among five major development concepts. "The 13th Fiveyear Plan for national economic and social development of People's Republic of China" was released in Mar. 2016. Green development was listed as among the five development ideas (i.e. innovation, coordination, green, open and sharing). Furthermore, as President Xi Jinping mentioned repeatedly, "Lucid waters and lush mountains count as invaluable assets". Thus far, the green development has been consciously incorporated into the strategy of sustainable development adopted by all provinces and regions, and the economic growth has been decelerated. How to balance economic demand and limited supply of environmental resources, economic demand and environmental contamination should be reckoned with in the strategy for regional government development. How to effectively assess the state of green development has also aroused wide concerns from scholars both at home and abroad, which can be referenced to facilitate the implementation of green development strategy.

\subsection{The Origin and Relationships of Green Development}

Green development counts as the specific orientation of sustainable development [1], commonly perceived as the intersection of environment, society, and economy [2].
Green growth seeks to grow and develop the economy, "growth resource-efficient, cleaner and more resilient without getting slowed" [3], while ensuring the sustainable natural assets, resources and environmental services [4]. The green position, green consumption, green agriculture, green manufacturing, green circulation, green city, green area development, green energy resources and other aspects were elaborated in 13th FiveYear plan, and the concept of "green development" was also optimized [5]. The essence and connotation of green development were as follows: "the resources and energy should be rationally utilized, the economic society should be moderately developed, the damage compensation and the harmonious coexistence of man and nature should be balanced," as asserted by Jiang Nanping (2013) [6].

As the financial crisis broke out globally in 2008 , green development had progressively become a path for numerous countries to cope with multiple challenges, inclusive of resources and environment [7]. And primary challenges bound by environmental / ecological, social, cultural, economic and technological factors require to be highlighted given the increased urban expansion [8]. Finland, Britain and Germany started to levy a carbon tax [9]. "Who is polluting, who is harnessing," was pointed out by The CERCLA in the United States, and the liability insurance business was also introduced. The carbon emission management planning has been involved by UK into the government budget, seeking to facilitate the green development largely from the green aspects of energy, manufacturing and lifestyle [10]. Environmental objectives were pursed by Israel as public investment and

\footnotetext{
* Corresponding author: 2015225020124@stu.scu.edu.cn; Tel.: +86-18200599492
} 
taxation policies, inclusive of cancel fiscal incentives capable of promoting activities harmful to environment [11]. United Nations Environment Program realized 2\% of the world GDP should be invested to agriculture, buildings, energy, fisheries, forests, manufacturing, tourism, transport, water and waste management, which can successfully expedite the transition of a low carbon economy, resource-saving society [12]. The GDP and per capita GDP have higher growth as the green economy seeks to promote natural capital appreciation.

\subsection{The Dissipative Characteristics of Regional Green Development}

The 3E system of city was primarily manifested as openness, non-equilibrium and nonlinear, as analyzed by Bi Hongjie (2013) [13]. How to adopt it to regional, provincial and national areas? The logical diagram as shown in Figure 1 is carried out in line with the characteristics of green development.

First and foremost, regional system counts as an open system. Regional development shall comprehensively exchange the material, energy and information. The input of production factors (e.g. energy, human, capital and technology) shall bring economic output and ultimately elevate the consumption level of the residents. The era of information and big data counts as a good example to the open system.

Second, regional green development refers to a course of continuous imbalance. For instance, energy consumption and capital consumption shall create not only the economic output but the environmental contamination. Accordingly, this refers to the imbalance between input and output from the perspective of environment subsystem. On that basis, the health problem and limited economic development shall occur. Additionally, the internal subsystem shall also be imbalanced. For instance, the production factors are unevenly distributed in various regions and industries. Merely the imbalance between subsystems was discussed in this paper.

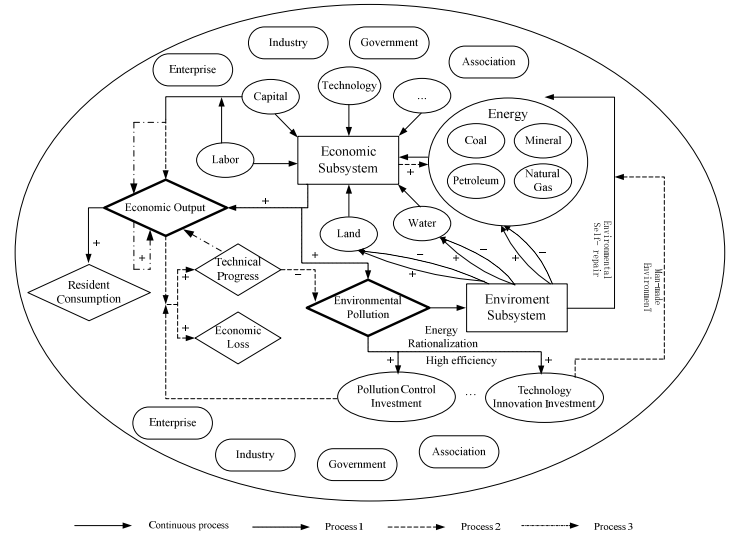

Fig. 1. Dissipative Structure Diagram of Green Development Third, the subsystems are nonlinearly related to the influencing factors of regional green development. Given the considerable elements and complex relationships [13] in society, the correlation can be ascertained with statistical method as all factors impossibly take on the absolute linear relation. The nonlinear relationship makes every step of development hard to accurately predict, whereas increases the possibility and variability. Furthermore, new overall effects can be formed other than single subsystem.

Fourth, fluctuation must happen under the combined action of foregoing three characteristics. The continuous exchange of energy, capital and information in internal and external system, accompanied by continuous imbalance process and a nonlinear relationship, the economic output and other outputs shall be inevitably changed as influence factor is entered or withdrawn.

The novelties of this paper are primarily manifested in three aspects. First and foremost, the theory of dissipative structure and the concept of information entropy are introduced to build the evaluation index system. The indicators of each subsystem fall into positive entropy and negative entropy index, reflecting the pressure and benefits of that subsystem, respectively, other than incorporating the indicators and standardizing the inverse indexes [14-17]. Second, given that nation wealth is comprised of produced capital, natural resources and human resources, this paper factors in the all-around input-output principle to make green development more logical [18]. As the nature resources are inputted, capital and labor factors are also selected. Economic output and environmental pollution are also presented in the index system. Third, the 30 provinces are selected as the research objects, and 8-year data are inputted adopting fixed base range method 1 other than pure cross section data or time series data [19-22], to anatomize the difference of the green development of the entire country and provinces. Additionally, the results of each year are comparable.

This paper is organized as follows: firstly, the situation of green development and the necessity of this research are introduced; the empirical model and theory shall be expounded, followed by data input and calculation; eventually, the results shall be anatomized, and the conclusion of this study shall be drawn.

\section{Methodology}

\subsection{Brusselator Model of Green Development}

Brusselator model counts as a dynamic model for evolving the dissipative structure. In the original formula, $\mathrm{A}$ and $\mathrm{B}$ are regulated as initial reactants and consumed continuously in chemical reaction, able to be added to the external supplement. D and E serve as the products, able to be taken away as soon as ensured constantly. $\mathrm{X}$ and $\mathrm{Y}$ serve as reaction factors in the reaction $[19,23,24]$. The model is as presented below:

$$
A \stackrel{k_{1}}{\rightarrow} X
$$

\footnotetext{
1 “China Green Development Index Report 2016”, Beijing Normal University Publishing Group
} 


$$
\begin{gathered}
B+X \stackrel{k_{2}}{\rightarrow} Y+D \\
2 X+Y \stackrel{k_{3}}{\rightarrow} 3 X \\
X \stackrel{k_{4}}{\rightarrow} E
\end{gathered}
$$

\subsection{Calculation Process}

\section{(1) Index standardization}

The fixed base range method is employed to standardize the original data $\left(a_{t}\right)$ given the negative values in the index system with time attribute, which makes the index value readily controllable in the range 0 1 , and the data processing results in different years are comparable. The processing equation is presented below:

$$
x_{i j}^{t}=\frac{a_{i j}^{t}-\operatorname{mina}_{i j}^{t 0}}{\max a_{i j}^{t 0}-m i n a_{i j}^{t 0}}
$$

Where, $b_{i t}$ denotes the value of the $\mathrm{i}$-th index of the $\mathrm{t}-$ th year. And 2008 is denoted as the 00 year in this paper.

(2) The information entropy and the weight of index

Given that the information entropy can effectively describe the order degree of organizational system, it is more scientific than thermodynamic entropy and statistical mechanical entropy. The greater the entropy value of information entropy means the organization is more chaotic, and the order degree of the organization is lower. In this regard, the entropy weight of the index also reflects the order of the corresponding index. The entropy and the weight of evaluation index are expressed as:

$$
\begin{gathered}
e_{i}=-\frac{1}{\ln n}\left(\sum_{j=1}^{n} f_{i j} \ln f_{i j}\right) \\
f_{i j}=\frac{1+x_{i j}}{\sum_{j=1}^{n}\left(1+x_{i j}\right)} \\
w_{i}=\frac{1-e_{i}}{\sum_{i=1}^{m}\left(1-e_{i}\right)}
\end{gathered}
$$

where $w_{i j}$ denotes index weight for $\mathrm{i}$-th index of $\mathrm{j}$-th province, and $x_{i j}$ bespeaks the index standardized value.

(3) Level of green development

The weight of the index and the value of the index are determined. Accordingly, the state of green development in each subsystem represented can be calculated via the function below, with the concept of positive and negative entropy.

$$
\begin{gathered}
G D_{j}=\sum w_{i} x_{i} \\
\triangle G D_{j}=\left|G D_{j}^{-}\right|-\left|G D_{j}^{+}\right|
\end{gathered}
$$

$G D_{j}^{-}$deonotes the negative entropy evaluation, and $G D_{j}^{+}$refers to the positive entropy evaluation.

Two subsystems are contained in this paper, thus the total level of green development also can be added over.

$$
\triangle G D=\triangle G D_{1}+\cdots+\triangle G D_{j}
$$

\section{Evaluation Index System of Green Development Level}

2 “+” represents negative entropy index, “-” represents positive entropy index.
The proportion of economic indicators has dropped to $21 \%$, and the proportion of non-economic indicators, with energy saving and emission reduction included, has risen

\begin{tabular}{|c|c|}
\hline \multicolumn{2}{|l|}{ Indicator names } \\
\hline Per capita GDP (yuan/person) & $+^{2}$ \\
\hline Household consumption expenditure by region (yuan) & + \\
\hline 1-Engel coefficient of rural residents (\%) & + \\
\hline Reutilization rate of water resources (\%) & + \\
\hline $\begin{array}{l}\text { Proportion of employed personnel in the tertiary } \\
\text { industry }(\%)\end{array}$ & + \\
\hline Rate of water saving irrigation (\%) & + \\
\hline $\begin{array}{l}\text { Proportion of effective irrigation area to cultivated } \\
\text { land }(\%)\end{array}$ & + \\
\hline Rate of industrial solid wastes utilized (\%) & + \\
\hline $\begin{array}{l}\text { Workforce Productivity of primary industry (10000 } \\
\text { yuan/person) }\end{array}$ & + \\
\hline $\begin{array}{l}\text { Workforce Productivity of secondary industry ( } 10000 \\
\text { yuan/person) }\end{array}$ & + \\
\hline $\begin{array}{l}\text { Workforce Productivity of tertiary industry (10000 } \\
\text { yuan/person) }\end{array}$ & + \\
\hline $\begin{array}{l}\text { Investment in fixed assets of primary industry (100 } \\
\text { million yuan) }\end{array}$ & - \\
\hline $\begin{array}{l}\text { Investment in fixed assets of secondary industry (100 } \\
\text { million yuan) }\end{array}$ & - \\
\hline $\begin{array}{l}\text { Investment in fixed assets of tertiary industry (100 } \\
\text { million yuan) }\end{array}$ & - \\
\hline $\begin{array}{l}\text { Energy consumption per unit of GRP (ton of } \\
\text { SCE/10000 yuan) }\end{array}$ & - \\
\hline $\begin{array}{l}\text { Power consumption per unit of GRP (kwh / } 10000 \\
\text { yuan) }\end{array}$ & - \\
\hline $\begin{array}{l}\text { Water consumption per unit industry value added } \\
\text { (cu.m/10000yuan) }\end{array}$ & \\
\hline $\begin{array}{l}\text { Sulphur dioxide emission per unit of GRP (tons/100 } \\
\text { million yuan) }\end{array}$ & - \\
\hline $\begin{array}{l}\text { Smoke dust discharge per unit of GRP (tons/ } 100 \\
\text { million yuan ) }\end{array}$ & - \\
\hline $\begin{array}{l}\text { Nitrogen oxides emission per unit of GRP (tons/ } 100 \\
\text { million yuan ) }\end{array}$ & - \\
\hline $\begin{array}{l}\text { COD discharge per unit of GRP (tons/ } 100 \text { million } \\
\text { yuan ) }\end{array}$ & - \\
\hline $\begin{array}{l}\text { Ammonia nitrogen discharge per unit of GRP (tons/ } \\
100 \text { million yuan ) }\end{array}$ & - \\
\hline $\begin{array}{l}\text { In economic subsystem, the present situati } \\
\text { economic development and the amelioration } \\
\text { industry can be reflected by economic level and ind } \\
\text { amelioration to ensure the sustainable development } \\
\text { economy. Labor force, capital investment and } \\
\text { consumption primarily shall be spent and drawn } \mathrm{u} \\
\text { the production. The productive investment in Brus }\end{array}$ & $\begin{array}{l}\text { of } \\
\text { the } \\
\text { strial } \\
\text { f the } \\
\text { hergy } \\
\text { on in } \\
\text { lator }\end{array}$ \\
\hline
\end{tabular}
by nearly $80 \%$ in the "11th Five-Year plan". Besides, economic development indicators were replaced by more environmental evaluation indicators. Accordingly, a comprehensive and feasible evaluation index system is established as listed in Table 1 and Table 2 on the basis of the necessity and actual situation of economic development, resources and environment in green development, and abiding by the principles of science.

Table 1. Index system of Green Economic Development Level 
model can fall into labor and capital factor. Yet the capital investment and energy consumption are introduced into positive entropy index system arising from their different impacts in green development. Additionally, the environmental pollution stemmed from human behavior and economic development shall disturb green development and serve as the positive entropy.

Table 2. Index system of Green Environment Support Level

\begin{tabular}{|c|c|}
\hline \multicolumn{2}{|l|}{ Indicator names } \\
\hline Per capita water resources (cu.m/person) & + \\
\hline Forest area per person ( hectares/person) & + \\
\hline Forest coverage rate $(\%)$ & + \\
\hline Percentage of nature reserves in the region (\%) & + \\
\hline Proportion of wetlands in total area of territory $(\%)$ & + \\
\hline Standing forest stock per person (cu.m/person) & + \\
\hline $\begin{array}{l}\text { Proportion of environmental expenditure in financial } \\
\text { expenditure }(\%)\end{array}$ & + \\
\hline $\begin{array}{l}\text { Investment in anti-pollution projects as percentage of } \\
\text { GDP }(\%)\end{array}$ & + \\
\hline Added area of afforestation (hectares/10000 persons) & + \\
\hline Area of urban green area(hectare/person) & + \\
\hline Green coverage rate of constructed areas (\%) & + \\
\hline $\begin{array}{l}\text { Coverage rate of urban population with access to tap } \\
\text { water }(\%)\end{array}$ & + \\
\hline Waste water treatment rate $(\%)$ & + \\
\hline Treatment rate of consumption wastes (\%) & + \\
\hline $\begin{array}{l}\text { Sulphur dioxide emission per unit land area } \\
\text { (tons/ } 1000 \text { hectares) }\end{array}$ & - \\
\hline $\begin{array}{l}\text { Sulphur dioxide emission per person (tons } / 10000 \\
\text { persons) }\end{array}$ & - \\
\hline $\begin{array}{l}\text { Smoke dust discharge per unit land area (tons } / 1000 \\
\text { hectares) }\end{array}$ & - \\
\hline $\begin{array}{l}\text { Smoke dust discharge per person (tons/ } 10000 \\
\text { persons) }\end{array}$ & - \\
\hline $\begin{array}{l}\text { Nitrogen oxides emission per unit land area } \\
\text { (tons/1000 hectares) }\end{array}$ & - \\
\hline $\begin{array}{l}\text { Nitrogen oxides emission per person (tons/ } 10000 \\
\text { persons) }\end{array}$ & - \\
\hline $\begin{array}{l}\text { COD discharge per unit land area (tons } / 1000 \\
\text { hectares) }\end{array}$ & - \\
\hline COD discharge per person (tons/10000 persons) & - \\
\hline $\begin{array}{l}\text { Ammonia nitrogen discharge per unit land area } \\
\text { (tons/1000 hectares) }\end{array}$ & - \\
\hline $\begin{array}{l}\text { Ammonia nitrogen discharge per person (tons } / 10000 \\
\text { persons) }\end{array}$ & - \\
\hline $\begin{array}{l}\text { Fertilizer use per unit cultivated land (tons/ } 1000 \\
\text { hectares) }\end{array}$ & - \\
\hline $\begin{array}{l}\text { Diesel use per unit cultivated land (tons/ } 1000 \\
\text { hectares) }\end{array}$ & - \\
\hline $\begin{array}{l}\text { Pesticide use per unit cultivated land (tons/ } 1000 \\
\text { hectares) }\end{array}$ & - \\
\hline Number of environmental emergencies (time) & - \\
\hline
\end{tabular}

In environment subsystem, i.e. the green environment support, the resource factors are presented as the secondary indicator - resource reserve to reflect the

\footnotetext{
${ }^{3}$ The maps of China in the article only embody the provinces
} of China and do not contain sea areas and islands. present situation of natural environment in contrast with economic level. On that basis, the environmental construction is encompassed by three aspects, i.e. government support, environmental restoration and urban living environment. Lastly, the environmental loadable pressure is basically denoted by the pollutant emission indexes (per unit land area and per person) to manifest the spatial perspective from atmosphere to soil.

\section{Data and Result Analysis}

The green development level of 30 provinces in mainland of China (except Tibet) from 2008 to 2015 are analyzed in this paper on the basis of the foregoing analysis theory and index system. The original data are originated from "China Statistical Yearbook 2016", "China Statistical Yearbook on Environment 2009-2016" and "China Rural Statistical Yearbook 2009-2016”.

\subsection{Analysis on Green Development Level}

The entire country takes on overall decline in the state of green development through the comparison in Figure 2. The concrete explanation is presented below:
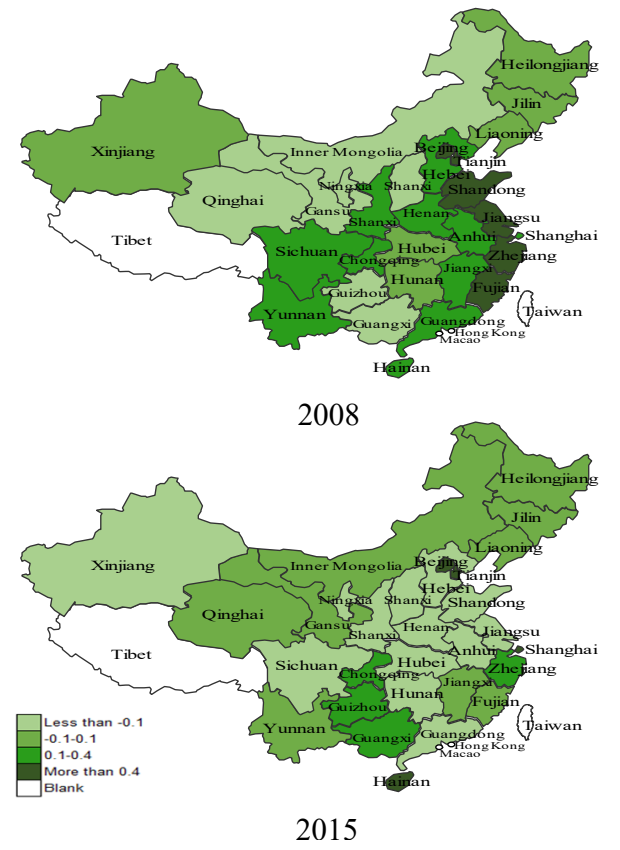

Fig. 2. Green Development Level ${ }^{3}$

(1) The green development state in Eastern China overall declines in ranking. For these 10 provinces, 8 provinces ranked the top 10 in 2008 and Beijing, Tianjin, Shanghai have been the top 4 since 2011, the other provinces are indicated on the decline. In 2015, Shanghai and Hainan increase 0.62 (maximum value of the increase in 30 provinces) and 0.432 in the state of green development. Hebei, Jiangsu, Fujian, Shandong, and Guangdong are negative in values, merely taking up half and ranked far from the top 10. Among these provinces, Shandong and Hebei decline evidently in the green 
development state, by -1.275 (maximum value of the decline in 30 provinces) and -0.967 , respectively.

(2) Central China takes on the most evident decline in the green development states, with the lowest regional ranking. All values of six provinces in the midland have been reduced since 2008, and are negative taking on larger decline rates in 2015. In 2015, 5 provinces (Shanxi, Jiangxi, Henan, Hubei, Hunan) dropped to the 20th-30th, whereas only Jiangxi ranked 14th. Henan is the province taking on lowest state of green development from 2013 to 2015 , and value is -0.983 in 2015 , which dropped from 0.123 in 2008.

(3) The green development states in Western China are on the rise. Rankings of provinces are overall risen or maintained with the exception of Sichuan and Shanxi province. Inner Mongolia, Chongqing, Guizhou, Yunnan squeezed into top 10 in 2015. Guizhou took on the largest increase (0.502) on ranking. The green development states of the Western provinces, compared with those of provinces in Eastern and Central China, are evenly distributed, with the smallest gap among them.

(4) Northeastern China is evidently fluctuated in green development state. Liaoning, Jilin and Heilongjiang have increased progressively in the 8-year development. The ranking of Liaoning has declined continuously, and suddenly increased to 17 th in 2015 from 29th in 2012. The ranking of Jilin has risen continuously. Heilongjiang rose from 15th in 2011 to the 1th in 2012, with the value increased from -0.597 to 1.769 . Since then, this province dropped to 28th in 2013.

\subsection{Analysis on Green Economic Development Level}

Most eastern, midland and western provinces are less than -0.1 in green economic development level, as indicated from Figure 4. Distribution complies with the overall state of green development (Figure 2). The negative entropy of most provinces reached the bottom in 2010 arising from the declining values of industrial progress. The low quality of green economic development can be indicated combining with increasing negative entropy after 2011 and policies to slow down economic development. The specific spatial distribution is expressed below:

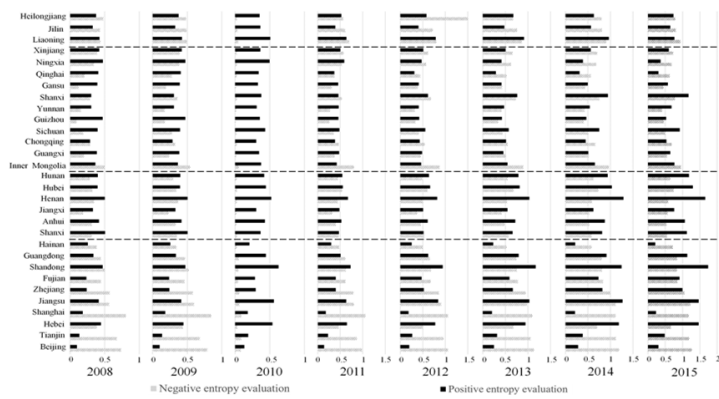

Fig. 3. Entropy Evaluation Value of GEDL
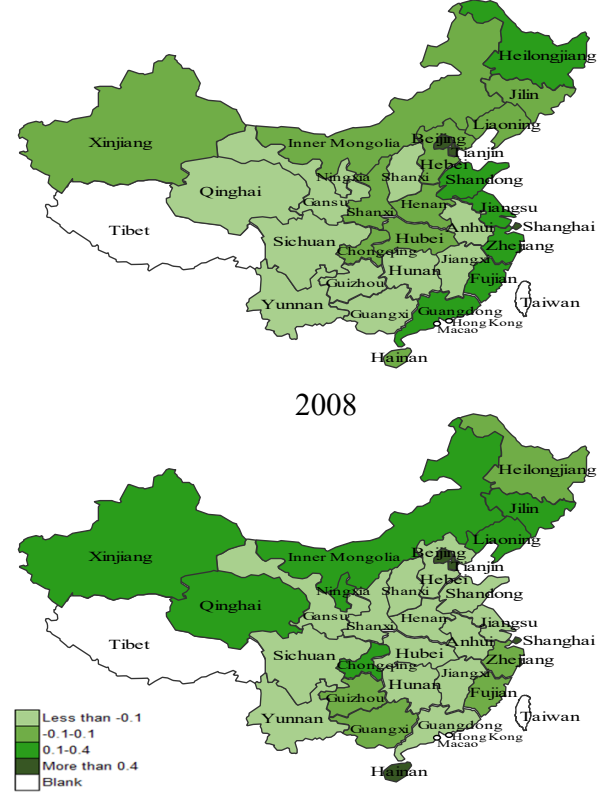

2015

Fig. 4. Green Economic Development Level

(1) The increase in positive entropy surmounts that of negative entropy of Eastern China, and the state of green economic development overall drops. Beijing, Tianjin and Shanghai, as developed areas, have been maintained as top 4 since 2011, and their negative entropy values evidently surmount the positive entropy. Merely the positive entropy of Hainan decreases by 0.1052 , whereas the negative entropy increases by 0.32685 . In this regard, Hainan is ranked as the 4th in 2015. The energy cost evidently surmounts the economic benefit it brings, as bespoken from the differences between increase in negative entropy and increase in positive entropy of Hebei (-0.8357), Jiangsu (-0.4673), Zhejiang (-0.3015), Fujian ($0.2847)$, Shandong (-1.0450, the minimum value) and Guangdong (-0.448). The cost of energy consumption is not even reduced by the slowdown in economic development.

(2) The negative entropy of green economic development in Central China is constantly under the positive entropy, and the economic efficiency is the lowest. Henan province has ranked the bottom in green economic development with low since 2011 as the positive entropy has been apparently increased (1.2565 in 2015). The six provinces have been ranked the last 15 and all declined in 2015, with the exception of Jiangxi rising to 18 th from 24th in 2008. The difference of increase values - green economic development state are less than -0.35 in other four provinces (Shanxi, Anhui, Hubei, Hunan). In this regard, the quality problem of economic development requires to be stressed in Central China.

(3) The development levels of green economic in Western China rise. Merely three provinces (Sichuan, Yunnan, Shanxi) take on the real decline of state, though the green economic development values of six provinces are negative. Accordingly, eight provinces elevate their green economic development state, e.g. Qinghai and Ningxia rising to top 10 from 29th and 26th, respectively, and their positive entropy even decreases by 0.2 . Shanxi 
is the only province slipping in the ranking, with the largest increase (0.8724) in positive entropy.

(4) With fluctuated features, the results of green economic development in Northeastern China are different trend with that of green development level. Liaoning has showed a zigzag change from 2008 to 2011, and then kept 17th in next three years, up to 8th in 2015. Jilin is less volatile and has basically maintained at the top 10 in 2009-2015. These two provinces both improve on green economic development, while the value of green economic development of Heilongjiang is negative ($0.05)$. This phenomenon is just the opposite of green development level.

\subsection{Analysis on Green Environment Support Level}

The level of green environment support and the change degree are lower by and large than that of green economic development level in same province. In this regard, the difference of value among provinces is not apparent. The distribution of green environmental support state is little changed in 2008-2010 in China, and then values of positive entropy indexes surged in 2011. The support level of the national green environment takes on the decline in general.

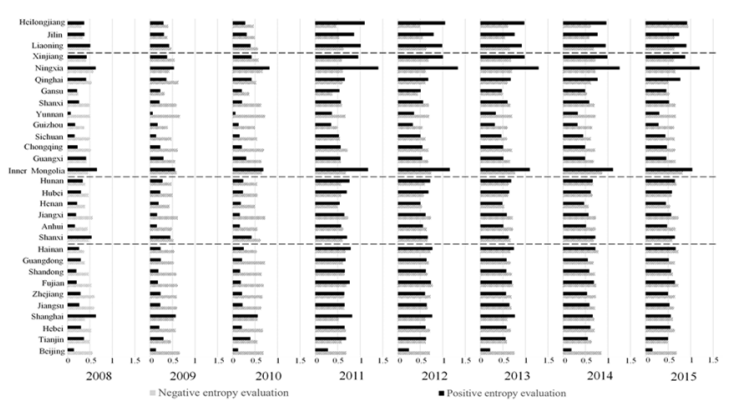

Fig. 5. Entropy Evaluation Value of GESL
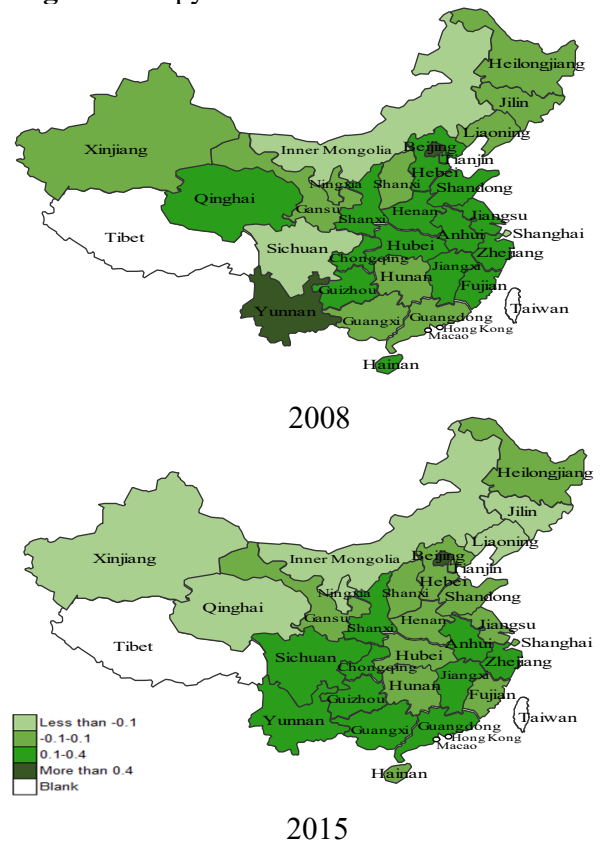

Fig. 6. Green Environment Support Level
(1) In excess of half provinces in Eastern China take on a decline in green environment support state and slide more in the rankings than values changed. Merely the final values of Beijing, Shanghai and Guangdong are positive. Beijing has been top1 for five years with a decreasing positive entropy, and Shanghai ranks 18th with merely negative increase (-0.0713) in positive entropy and the largest increase $(0.2865)$ in green environment support level. For other provinces, the environmental loadable pressure surmounts the resources reserve and environment construction, and the values range from -2.6 to -0.6 .

(2) Smaller change in ranking than other region, the green environment support levels of Central China first decrease, and then increase. Six provinces have increased by degrees since 2011 after dropping from 2008. Anhui (0.183) and Jiangxi (0.166) rank 7th and 8th, respectively, in 2015. Only the values of green environment support in Shanxi and Hubei are negative, thus the provinces in midland have laid the particular stress on environmental remediation with increasing negative entropy and positive entropy.

(3) Polarization development is prominent on green environment support level in Western China. The state values decrease in eight provinces and are negative for four provinces (Inner Mongolia, Qinghai, Ningxia, Xinjiang) in 2015. The change values of Qinghai and Ningxia are -0.377 and -0.493 (the maximum). The change value is -0.105 on the average, and regional gap is the most apparent. Since 2011, five provinces (Guangxi, Chongqing, Sichuan, Guizhou, Yunnan) have ranked top 10 , and other five provinces have ranked last 10.

(4) The support capacity of green environment in Northeastern China is the weakest and changed little. The three provinces all reached the minimum $(-0.38$ for Liaoning, -0.331 for Jilin, -0.63 for Heilongjiang) in 2011, but accompanied by different phenomena. The level values of Jillin and Heilongjiang have increased evidently, whereas that of Liaoning has been maintained to be unchanged. In contrast with results in 2008, Liaoning and Jilin both dropped in green environment support level and Heilongjiang rise in value.

\section{Conclusion}

As the green economic development state is analyzed, green environment support level of 30 provinces in China, different distribution and characteristics are identified. Accordingly, the final conclusions are concluded and supplemented on the basis of the foregoing description analysis.

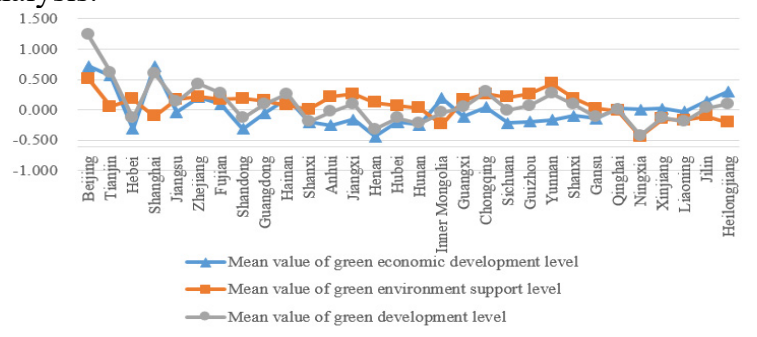

Fig. 7. Mean Value of 8-Year Results 
As bespoken from our findings, green economic development serves as the main orientation in China other than the improvement of the green environment benefit. First, the weights of two subsystems are the same cause the values are just added together to evaluate the final green development level. And it can be find in Figure 7 that the final result is closer to the value of green economic development. Second, negative entropy of green economic grow slower than positive entropy, and it can reflect the higher and higher energy cost and low quality of green economic development. Third, the evaluation value and range of green environment support are far less than that of green economic development and the positive entropy of green environment support has increased rapidly since 2011 . The two facts can illustrate the persistent high pressure of environmental space.

Our findings uncover a widening gap distribution among regions on green development level and the promotion of green economic development is still at the expense of the green environment. The abscissa is indicated to be progressively expanded by time. First and foremost, the Eastern China takes on the decline both in green economic development and green environment support, whereas remains the region with the highest average arising from strong resource base. In 2015, four provinces are listed in top 10 at the level of green economic development, whereas only the green environment support level of two provinces are maintained in same level, and the number of provinces between 11th to 20th are two and seven, respectively. Most provinces are in the middle level. Second, the overall green environment support state surmounts green economic development level in Central China, though the levels both decline in 8-year process. The values of green economic development in six provinces are negative all the time and the rankings are basically in the last 15 , which differs from the distribution on green environment support. Third, the opposite changes are indicated in two subsystems of Western China and Northeastern China, which bespeaks the environment cost inputted in economic growth. The green economic development state of most provinces is evidently elevated, whereas the relative state of green environment support is declined. In this regard, the gap of green economic development level among the provinces in the Western China is the smallest, and the gap of green environment support level is the largest. And the three provinces in northeastern are the top 15 at the green economic development level and the last 15 at the green environment support level.

This study primarily seeks to assess the green development state of 30 provinces in China from the green economic and green environment perspectives. The effective and credible results are identified through designing this data analysis. Also, this paper takes on some limitations. First and foremost, the final state of green development can be impacted by the weight of green economic and green environment subsystem. Also, the identical weight is employed in this paper to avoid subjective risk. Accordingly, the analysis results in this paper are drawn upon merely to analyze the time change and regional distribution. Second, more indicators should be introduced with the development of public data statistics. The relative issues for analyzing green development efficiency and influencing factors shall be highlighted in the future to improve the results of existing research.

\section{Acknowledgments:}

This research is supported by "the Fundamental Research Funds for the Central Universities".

\section{References}

1. H.D. Witt, Sustainability 6(11), 8310-8328 (2014)

2. B. Giddings, B. Hopwood, G. O'Brien, Sustainable Development 10(4), 187-196 (2002)

3. S. Hallegatte, G.M. Heal, M. Fay, D. Treguer, Policy Research Working Paper, (2016)

4. G.G.K. Platform, Green Growth Knowledge Platform, 1-44 (2013).

5. X.X. Wu, S.Y. Zhang, On Economic Problems 2, 3034 (2017)

6. N.P. Jiang, R.K. Xiang, Contemporary Economic Research 2, 50-54 (2013)

7. H.X. Zheng, Y. Wang, B.R. Huang 2, 142-152 (2013).

8. S. Uno, Sustainable Development, Knowledge Society and Smart Future Manufacturing Technologies, 81-112 (2010).

9. M. Zhang, International Studies 5, 93-102 (2013).

10. Y.Y. Yang, X.X. Wu, Z.K. Yang, Journal of Xinjiang Normal University (Philosophy and Social Sciences) 38(2), 18-24 (2017).

11. 16, 8-37 (2011).

12. United Nations Environment Program. Nairobi Kenya Unep (2011).

13. H.G. Bi, Y.G. Feng, Journal of Systems Science 21(4), 93-96 (2013).

14. W. Zhang; Y.Y. Zhou, S.X. Xie, World Regional Study 22(4), 134-142 (2013).

15. S.F. Hu, X.F. Ma, Science and Technology Management Research 7, 110-114 (2017)

16. L.J. Si, Lanzhou Academic Journal 3, 179-183 (2016)

17. P. Dai, Qinghai Social Sciences 3, 170-177 (2015)

18. T.W. Bank, World Bank (2006)

19. J. Zhang, Knowledge Economy 1, $72-73$ (2014)

20. B. Liu, L. Zhang, Inquiry into Economic Issues 7, 141-152 (2017)

21. R.D. Ge, C.X. Yu, Y. Xu, Journal of Dalian Minzu University 19(1), 48-54 (2017)

22. H.X. Li, F.B. Kong, S.D. Chen, Hubei Social Sciences 8, 68-76 (2017)

23. Y.H. Yu, F.X. Lv, C.H. Tang, Journal of Business Economics 1, 34-41 (2014)

24. T.N. Zhang, B.Y. Cheng, Y.J. Zhang, Journal of Industrial Engineering / Engineering Management 3, 103-108 (2010) 